\title{
Cholestasis of pregnancy: a prospective analysis from a South Andaman teaching hospital
}

\author{
Bhabani Pegu*, Manju Mehrotra, Anita Yadav, Pinky S. K. Sahoo
}

Department of Obstetrics and Gynecology, ANIIMS Port Blair, Andaman and Nicobar Islands

Received: 04 February 2019

Accepted: 06 March 2019

\section{*Correspondence:}

Dr. Bhabani Pegu,

E-mail: bpeguamc@gmail.com

Copyright: () the author(s), publisher and licensee Medip Academy. This is an open-access article distributed under the terms of the Creative Commons Attribution Non-Commercial License, which permits unrestricted non-commercial use, distribution, and reproduction in any medium, provided the original work is properly cited.

\begin{abstract}
Background: Intrahepatic cholestasis of pregnancy (IHCP) is one of the commonest pregnancy related liver disorder. Although the maternal course is usually benign, there is an increased risk of spontaneous preterm delivery, fetal compromise, meconium stained amniotic fluid and even intrauterine fetal demise. The objective of this study was to study the incidence of IHCP and its impact on maternal and perinatal outcome.

Methods: A prospective study carried out in 68 number of IHCP cases. Diagnosis was done on the basis of clinical and laboratory parameters. All the cases were followed up to the puerperium to find out maternal and perinatal outcome.

Results: The incidence of cholestasis of pregnancy was $2.73 \%$. Most $(88 \%)$ of the cases were presented with generalized pruritus, relived with ursodeoxycholic acid and complete recovery was observed after delivery. The rate of instrumental delivery was $8.82 \%$ and caesarean section rate was $30.88 \%$. Most common indication of caesarean section was fetal distress and non-progress of labour. There was one stillbirth at 35 weeks however none of the mother had complication during labour or puerperal period.

Conclusions: Increased level of liver enzymes in patients of IHCP associated with poor perinatal outcome. Therefore, careful monitoring during antenatal period and termination of pregnancy at term will result in favourable outcome of both mother and baby.
\end{abstract}

Keywords: Cholestasis, Feto-maternal outcome, Pregnancy

\section{INTRODUCTION}

Intrahepatic cholestasis of pregnancy (IHCP) is one of the commonest pregnancy related liver disorder. It is also known as Obstetrics cholestasis and is defined as generalised pruritus including palms and soles, late in pregnancy that resolve following delivery and may recur in future pregnancy. ${ }^{1,2}$ It is associated with elevated serum bile acid and aminotransferase level. The incidence of IHCP varies widely from $0.1-24 \%$ with geographical location and ethnicity. ${ }^{3,4}$ Incidence and Prevalence of IHCP in women of Indian origin are one percent and five percent respectively. ${ }^{5}$ The etiologic of IHCP is elusive, although current investigations suggest a combination of hormonal, genetic and inflammatory factors that impair bile secretory function which increases maternal serum bile acid and elevates the production of liver enzymes. ${ }^{6}$

According to several studies, although the maternal course is usually benign, there is an increased risk of spontaneous preterm delivery, fetal compromise, meconium stained amniotic fluid and even intrauterine fetal demise. ${ }^{7,8}$ Delivery of IHCP patient has been recommended on 37-38 weeks gestation as risk for fetal increases with advancing gestation age. ${ }^{9}$ Unfortunately no method of fetal monitoring proved a real prediction or 
reduction of risk of adverse perinatal outcomes. Routine tests for fetal monitoring such as cardiotocography (CTG) and umbilical artery Doppler also cannot predict fetal outcome, so further clinical trials are required to identify the most suitable monitoring modalities. With this background this study was conducted to find out the incidence of ICHP and its impact on feto-maternal outcome, when actively managed.

\section{METHODS}

A prospective study was carried out for one year in a teaching hospital of South Andaman district from March 2017 to April 2018. The institutional ethical committee approval and written informed consent from all cases was taken prior to conduct the study. A total of 68 women were diagnosed with intrahepatic cholestasis of pregnancy. The diagnosis of intrahepatic cholestasis of pregnancy was made on the basis of history, scratch marks, biochemical evidence of altered LFT and excluding other liver and dermatological disorders. To rule out other causes of pruritus, dermatological consultation was taken. Trans abdominal USG was done to rule out liver and gall bladder pathology. In addition to this, blood test for hepatitis B surface antigen and hepatitis $\mathrm{C}$ antibody was also conducted for all patients. The patients diagnosed with IHCP were treated by ursodeoxycholic acid (UDCA) $20 \mathrm{mg} / \mathrm{kg} /$ day in divided doses.

The courses of pregnancy of all IHCP patients were monitored carefully up to 38 weeks of gestation. All the Patients were followed up weekly along with liver function test (LFT). Fetal surveillance was done by daily recording of fetal movements, CTG, modified biophysical profile (BPP) or umbilical artery doppler twice weekly. Termination of pregnancy was done at 38 weeks of gestation either by induction of labour or by LSCS wherever indicated. At the time of delivery, gestational age, onset of labour and mode of delivery were noted. Intrapartum complications were observed carefully. Neonatal outcome and complications including meconium aspiration, fetal distress, Apgar score at 1 and 5 mins and need of NICU admission or any perinatal mortality were noted. LFT was repeated after 2 weeks of delivery.

\section{RESULTS}

Out of all deliveries, 68 numbers of pregnant women were diagnosed as intrahepatic cholestasis of pregnancy during one year of study period. The incidence was found to be $2.73 \%$. Maximum $(60.29 \%)$ number of patients were primigravida and most of them were belongs to 21 25 years, with the mean age of $23.4 \pm 3.4$ years. Out of all multiparous women most $(54.3 \%)$ of them had past history of intrahepatic cholestasis of pregnancy and $32.16 \%$ of them had history of intake of oral contraceptive pill. Table 1 shows the characteristics of patients with their age, parity and gestational age where as Table 2 shows biochemical characteristics of the patients.

Table 1: Patients particulars.

\begin{tabular}{|lll|}
\hline & $\begin{array}{l}\text { Min - Max } \\
\text { (Range) }\end{array}$ & Mean \pm SD \\
\hline Age (years) & $17-37$ & $23.4 \pm 3.4$ \\
\hline Parity (numbers) & $02-04$ & $1.31 \pm 1.9$ \\
\hline Gestational Age (weeks) & $28-37$ & $31.0 \pm 2.54$ \\
\hline
\end{tabular}

Table 2: Biochemical parameters of patients.

\begin{tabular}{|llll|}
\hline & $\begin{array}{l}\text { Reference } \\
\text { value }\end{array}$ & $\begin{array}{l}\text { Min - Max } \\
\text { (Range) }\end{array}$ & Mean \pm SD \\
\hline SGOT (U/L) & $17-59$ & $72-311$ & $150 \pm 30.81$ \\
\hline SGPT (U/L) & $21-72$ & $77-295$ & $117 \pm 28.61$ \\
\hline $\begin{array}{l}\text { Serum bilirubin } \\
\text { (mg/dl) }\end{array}$ & $0.2-1.3$ & $0.4-2.3$ & $0.82 \pm 0.5$ \\
\hline $\begin{array}{l}\text { Alkaline } \\
\text { phosphatase (U/L) }\end{array}$ & $38-126$ & $144-671$ & $338 \pm 129$ \\
\hline
\end{tabular}

Main symptom of IHCP was pruritus (88\%) which cause disturbed sleep (35\%) and scratch marks $(73 \%)$. With the use of Ursodexycholic acid, almost all women reported partial or complete relief of pruritus and also observed in reduction in serum transaminase and bilirubin level.

Table 3: Mode of delivery.

\begin{tabular}{|lll|}
\hline & Number & Percentage (\%) \\
\hline Normal delivery & 41 & 60.29 \\
\hline Instrumental delivery & 06 & 8.82 \\
\hline LSCS & 21 & 30.88 \\
\hline
\end{tabular}

Table 4: Pregnancy outcome.

\begin{tabular}{|lll|}
\hline & Number & Percentage (\%) \\
\hline Preterm labor & 3 & 4.41 \\
\hline PROM & 2 & 2.94 \\
\hline $\begin{array}{l}\text { Meconium stained } \\
\text { liquor }\end{array}$ & 12 & 17.64 \\
\hline LSCS & 21 & 30.88 \\
\hline Apgar < & 0 & 0 \\
\hline $\begin{array}{l}\text { Neonatal ICU } \\
\text { admission }\end{array}$ & 11 & 16.17 \\
\hline IUFD & 1 & 1.47 \\
\hline
\end{tabular}

Out of all IHCP patient LSCS was done in $30.88 \%$ of the patients and commonest indication was found to be fetal distress (Table 3). Three patients had preterm labour and two of them had premature rupture of membrane (PROM). Most of the patient went into labour spontaneously and some of them needed induction. Almost $81 \%$ of patients had fetal birth weight of more than $2.5 \mathrm{~kg}$ and there were no scores less than 7 in 5 minutes of APGAR. Total 11 numbers of newborn had NICU admission due to meconium aspiration, 
prematurity and low birth weight (Table 4). None of the IHCP mother had complication during labour or in puerperal period.

\section{DISCUSSION}

The incidence of intrahepatic cholestasis varies widely. In our hospital incidence of IHCP was found to be $2.73 \%$ during one year of study period and the mean age was $23.4 \pm 3.21$ years. The result of our study are comparable to the study done by Sharma $\mathrm{N}$ et al, although some studies reported relatively higher mean age. ${ }^{10,11}$ Most of the women presented after 30 weeks of gestation which is similar to other study findings. ${ }^{12}$ Generalised pruritus was the most common symptom with biochemical alterations of elevated serum bile acid and transaminase. Four patients had generalised pruritus with normal liver enzymes while repeat after one week, found to be elevated. Similar results were seen in two cases in the study done by Sharma $\mathrm{N}$ et al. ${ }^{10}$ Study conducted by Alakananda et al found serum bile acids and liver enzymes were raised in $100 \%$ cases. $^{13}$ It has been reported that itching may be presented either before or after abnormal liver function test and this may reflect the heterogeneous nature of this condition. ${ }^{14}$ According to some studies, when serum bile acid level goes beyond $40 \mathrm{mmol} / 1$, there is increased risk of preterm delivery (up to $19-60 \%$ ), meconium staining amniotic fluid (up to $27 \%$ ), fetal bradycardia (up to $14 \%$ ), fetal distress (22$41 \%$ ) and fetal loss (up to $0.4-4.1 \%$ ). ${ }^{15,16}$

In present study there was no significant adverse maternal outcome but had increased incidence of instrumental delivery and LSCS which was also seen in other studies. ${ }^{17-20}$ Higher rate may be due to active management or complication of the disease. Most common indications for LSCS were fetal distress and non-progress of labour. Those women who had started labour spontaneously, the percentage of normal delivery was high. All women with IHCP were given UDCA for reduction of pruritus, biochemical parameters and various perinatal complications. Although mechanism of action of UDCA is not fully understood, it has been postulated that UDCA works by displacing hydrophobic endogenous bile salts from the bile acid pool, protecting hepatocytes from their toxic effects and enhancing bile acid clearance across the placenta from fetus. ${ }^{21}$ Coagulation profile was done for all IHCP women and it was within normal limit, none of the women had postpartum haemorrhage. The finding was quite different from other studies where the rate of postpartum haemorrhage was high in women who did not receive vitamin $\mathrm{K} .{ }^{11,12}$

In present study mean gestational age at delivery was 37 weeks and there was no neonatal mortality. The incidence of preterm delivery $(4.41 \%)$ were relatively less as compare to study of Alakananda et al where it was as high as $23 \%$. Inspite of having meconium staining liquor (17.64\%), almost all the babies had normal APGAR score. It shows that most of the meconium staining liquor seen in IHCP is not because of fetal distress but due to bile acid, causes increase colonic motility and meconium passage. ${ }^{21}$ One woman had intrauterine feat death at 35 weeks of gestation inspite of getting UDCA and regular check-up. The cause of IUFD may be due to acute anoxic event due to direct cardio toxic effect of bile acid or vasoconstriction of placental vessel. ${ }^{3,9}$

\section{CONCLUSION}

Intrahepatic cholestasis of pregnancy is mostly associated with poor perinatal outcome which correlate with raised serum transaminase level. Proper monitoring during antenatal period and termination of pregnancy at term improve the perinatal outcome. The rate of LSCS is higher in IHCP cases owing to active management.

\section{ACKNOWLEDGMENTS}

Authors would like to thank all the patients for being a part of this research activity.

\section{Funding: No funding sources \\ Conflict of interest: None declared}

Ethical approval: The study was approved by the Institutional Ethics Committee

\section{REFERENCES}

1. Ambros-Rudolph CM, Glatz M, Trauner M, Kerl H, Müllegger RR. The importance of serum bile acid level analysis and treatment with ursodeoxycholic acid in intrahepatic cholestasis of pregnancy: a case series from central Europe Archives of dermatology. 2007;143(6):757-62.

2. Ambros-Rudolph CM, Müllegger RR, VaughanJones SA, Kerl H, Black MM. The specific dermatoses of pregnancy revisited and reclassified: results of a retrospective two-center study on 505 pregnant patients. J Am Acad Dermatol. 2006;54(3):395-404.

3. Geenes V, Williamson C. Intrahepatic cholestasis of pregnancy. World J Gastroenterol. 2009;15(17):2049-66.

4. Lee RH, Goodwin TM, Greenspoon J, Incerpi M. The prevalence of intrahepatic cholestasis of pregnancy in a primarily Latina Los Angeles population. J Perinatol. 2006;26(9):527-32.

5. UK: Royal College of Obstetricians and Gynaecologists Obstetric cholestasis Green-Top Guideline No 43. rcog.org. Available at: http://www.rcog.org.uk. Accessed June 2017.

6. Lammert F, Marschall HU, Glantz A. Intrahepatic cholestasis of pregnancy: molecular pathogenesis, diagnosis and management. J Hepatol. 2003;33:1012-21.

7. Heinonen S, Kirkinen P. Pregnancy outcome with intrahepatic cholestasis. Obstet Gynaecol. 1999;94:189-93. 
8. Catherine W, Laura H, Dimtrios G. Clinical outcome in a series of cases of obstetrics cholestasis identified via a patient support group. BJOG. 2004;111:676-81.

9. Kondrackiene J, Kupcinskas L. Intrahepatic cholestasis of pregnancy- current achievements and unsolved problems. World J Gastroenterol. 2008;14(38):5781-8

10. Sharma N, Panda S, Santa Singh A. Obstetric outcome during an era of active management for obstetrics cholestasis. J Obstet Gynecol India. 2015:1-4.

11. Pata O, Vardareli E, Ozcan A. Intrahepatic cholestasis of pregnancy: correlation of preterm delivery with bile acids. Turk J Gastroenterol. 2011;22(6):602-5.

12. Ray A, Tata RJ, Balsara R. Cholestasis of pregnancy. J Obstet Gynecol India. 2005;55:247-50.

13. Alakananda, Bhattacharrya A, Kavita. Feto-maternal Outcome in intrahepatic cholestasis of pregnancy. Sch J App Med Sci. 2016;4(10D):3837-41.

14. Kenon AP, Piercy CN, Gorling J. Obstetric cholestasis, outcome with active management: a series of 70 cases. BJOG. 2002;109:282-8.

15. Glantz A, Marschall HU, Mattsson LA. Intrahepatic cholestasis of pregnancy: relationship between bile acid levels and fetal complication rates. Hepatol. 2004;40:467-74.

16. Singh G, Sidhu MK. Cholestasis of pregnancy: A prospective study 2007. MJAFI. 2008;64:343-5.
17. Padmaja M, Bhaskar P, Kumar GJ, Seetha R, Mahasweta C. A study of obstetric cholestasis. J Obstet Gynecol India. 2010;60(3):225-31.

18. Dang A, Agarwal N, Bathla S, Sharma N, Balani S. Prevalence of liver disease in pregnancy and its outcome with emphasis on obstetric cholestasis: An Indian scenario. $\mathrm{J}$ of Obstet Gynecol India. 2010;60(5):413-8.

19. Amita G, Tania K, Yudhishtervir G, Jyoti H. Cholestasis of pregnancy. J Obstet Gynecol India. 2009;59(4):320-3.

20. UK: Royal College of Obstetricians and Gynaecologists Obstetric cholestasis Green-Top Guideline No 43. rcog.org. Available at: http://www.rcog.org.uk. Accessed June 2017.

21. Germain AM, Kato S, Carvajal JA, Valenzuela GJ, Valdes GL, Glasinovic JC. Bile acids increase response and expression of human myometrial oxytocin receptor. Am J Obstet Gynecol. 2003;189(2):577-82.

Cite this article as: Pegu B, Mehrotra M, Yadav A, Sahoo PSK. Cholestasis of pregnancy: a prospective analysis from a South Andaman teaching hospital. Int J Reprod Contracept Obstet Gynecol 2019;8:1895-8. 